\title{
Effect of Vegetable Oils Feed Additives on Endoparasites Associated with Dewormed Racing Horses
}

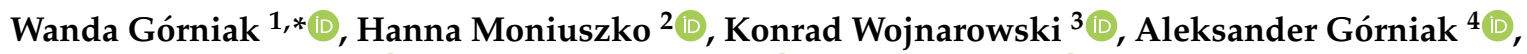 \\ Paulina Cholewińska $\left.^{3}{ }^{(}\right)$, Agnieszka Waliczek ${ }^{5}\left(\mathbb{D}\right.$, Maria Soroko ${ }^{3}{ }^{\circ}$ and Natalia Szeligowska ${ }^{3}$ \\ 1 Department of Environment Hygiene and Animal Welfare, Wrocław University of Environmental and \\ Life Sciences, Chełmońskiego 38C, 51-630 Wrocław, Poland \\ 2 Section of Applied Entomology, Department of Plant Protection, Institute of Horticultural Sciences, \\ Warsaw University of Life Sciences-SGGW, Nowoursynowska 159, 02-776 Warsaw, Poland; \\ hanna_moniuszko@sggw.edu.pl \\ 3 Institute of Animal Breeding, Wrocław University of Environmental and Life Sciences, Chełmońskiego 38C, \\ 51-630 Wrocław, Poland; konrad.wojnarowski@upwr.edu.pl (K.W.); paulina.cholewinska@upwr.edu.pl (P.C.); \\ maria.soroko@upwr.edu.pl (M.S.); 119635@student.upwr.edu.pl (N.S.) \\ 4 Department of Automotive Engineering, Faculty of Mechanical Engineering, Wroclaw University of Science \\ and Technology, Na Grobli 13, 50-640 Wrocław, Poland; aleksander.gorniak@pwr.edu.pl \\ 5 Department of Animal Nutrition and Biotechnology, and Fisheries, Faculty of Animal Sciences, University of \\ Agriculture in Krakow, Al. Mickiewicza 24/28, 30-059 Kraków, Poland; \\ agnieszka.waliczek@student.urk.edu.pl \\ * Correspondence: wanda.gorniak@upwr.edu.pl
}

\section{check for} updates

Citation: Górniak, W.; Moniuszko, H.; Wojnarowski, K.; Górniak, A.; Cholewińska, P.; Waliczek, A.; Soroko, M.; Szeligowska, N. Effect of Vegetable Oils Feed Additives on Endoparasites Associated with Dewormed Racing Horses. Agriculture 2021, 11, 525. https:// doi.org/10.3390/agriculture11060525

Academic Editors: Vito Laudadio and Vincenzo Tufarelli

Received: 16 April 2021

Accepted: 2 June 2021

Published: 5 June 2021

Publisher's Note: MDPI stays neutral with regard to jurisdictional claims in published maps and institutional affiliations.

Copyright: (c) 2021 by the authors. Licensee MDPI, Basel, Switzerland. This article is an open access article distributed under the terms and conditions of the Creative Commons Attribution (CC BY) license (https:/ / creativecommons.org/licenses/by/ $4.0 /)$.

\begin{abstract}
The effectiveness of commonly used parasiticides decreases due to the drug resistance developed by many organisms. Therefore, the application of feed additives possessing antiparasitic properties may be helpful in limiting the burden of parasites. The aim of this research was to evaluate parasitological coefficients for endoparasites of regularly dewormed Arabian horses and Thoroughbreds, fed on a basal diet of oat and muesli with vegetable oils and/or without vitamin E. The observations revealed parasitic invasion in 25 of 27 examined horses. The most frequent in both breeds were Strongylidae-accounting for $86 \%$ of Thoroughbreds and $100 \%$ of Arabian horses. Strongyloididae were observed in 33\% of individuals representing both breeds while botflies were found in one Arabian horse and one Thoroughbred. Mean EPG coefficients for strongylids and strongyloidids were higher in Thoroughbreds (530 vs. 529 and 43 vs. 29, respectively), although the differences were not statistically significant. The addition of pure linseed oil significantly reduced the number of Strongylidae in fecal samples. The results indicate that properly selected plant additives obtained from arable crops may be helpful in limiting the numbers of drug-resistant strongylids.
\end{abstract}

Keywords: animal health; disease prevention; drug resistance; feed additives; linseed oil; nutrition

\section{Introduction}

Internal horse parasites are a considerable issue permanently affecting the health of animals. Endoparasitic infestations are most often subclinical and frequently are unnoticed by veterinarians, breeders and horse owners [1]. Despite increasing numbers of antiparasitic drugs, in many cases deworming is performed incorrectly and thus it turns out to be ineffective [2]. The problem of parasitosis in horses comes mostly down to routine deworming, usually twice a year, without prior coproscopic examination. This procedure only temporarily reduces the number of adult parasites susceptible to the drug used [3]. The latter, combined with a recurrent application of the same and/or close pharmacological agents, with ivermectin and praziquantel being most commonly used [4-6] leads to partial or complete resistance developed by many parasites, especially gastro-intestinal, which cannot be eradicated with these drugs anymore [7-12]. The parasites that have become or have been gradually becoming resistant to currently used preparations are representatives 
of Ascarididae, Strongylinae, Cyathostominae, Anoplocephalids and botflies from Gasterophilus spp. $[7,9,11,13,14]$. Parasitism of listed taxa entails digestive disorders, anemia, diarrhea and colic causing a reduction in the amount of consumed and absorbed nutrients which, in turn, leads to a decrease in growth rate, general fitness, sport performance and exercise capacity of animals $[15,16]$.

The high cost of anthelmintic preparations, the development of drug resistance by internal parasites and the risk of environmental drug contamination encourage taking preventive measures by administering animals with e.g., natural feed additives, potentially having antiparasitic properties. Such alternatives may be various types of plant extracts, probiotic preparations and/or vegetable oils [11,17-19]. The modes of action of plant anthelmintics are not fully understood, but it may be the result of the direct and indirect action of secondary plant chemicals that affect the survival, growth and development of parasites in the digestive system $[20,21]$. Literature data indicate that the best vegetable raw material for producing above mentioned additives could be obtained from garlic, oregano, black cumin and plants belonging to the genus basil, as well as mixtures of these plants $[22,23]$ The listed plant species have differentiated activity against nematodes and other parasites, both in humans and animals [24-26].

Vegetable oils are widely used in horse nutrition due to readily available sources of slow-release energy and high levels of unsaturated fatty acids [27]. Regardless of its type, each oil improves the condition of the horse's coat, mane and tail, as well as hoof horn [28]. Soybean oil is characterizd by a high content of omega- 6 fatty acids, including linoleic acid. It has anti-inflammatory and anti-allergic properties and supports the development of muscles without causing diarrhea or changes in fecal characteristics. Vegetable oils are recommended to increase energy demand, especially for sports and hard-working horses, because they slowly release energy without the hyperactivity effect [29]. Another commonly used oil is linseed oil. This is particularly recommended for horses with gastric problems and stomach ulcers. It possesses a protective effect on the mucosa of the digestive system, preventing food-induced irritation and supports peristaltic movements [30]. Likely due to these properties, linseed oil was listed among potentially anthelmintic natural substances applied to horses in the mid-20th century $[17,18]$. Its active ingredients include omega-3 fatty acids, phytoestrogens, flavonoids and lignans [31]. Linseed contains also possibly toxic and anti-nutritional compounds (e.g., amygdalin, lymarin, cyanides); however, intoxication in horses was not observed [32]. Oil producers ensure that compounds harmful to animals are removed during production.

The aim of this research was to evaluate and compare the effects of potentially antiparasitic vegetable oils addition, with or without vitamin $\mathrm{E}$, against endoparasitic nematodes and insects in regularly dewormed Arabian horses and Thoroughbreds.

\section{Materials and Methods}

The study did not require the consent of the Local Ethical Commission (Act of 15 January 2015 on protection animals used for scientific or educational purposes). The parasite samples were from the feces after defecation.

\subsection{Animals}

The research was conducted on a group of 27 adult horses (15 Thoroughbreds (xx); 12 Arabian horses (oo)), 3-5 years old, with an average body weight of $420.5 \pm 50.5 \mathrm{~kg}$. The horses were clinically healthy and in a good condition. The animals were housed in individual box stalls bedded on straw, without access to pastures, in one stable at Partynice Race Course (Wrocław, Poland). All stalls measured approximately $9 \mathrm{~m}^{2}$ and were cleaned six times a week, in the morning. The animals were dewormed according to standard veterinary practice with a preparation containing $12 \mathrm{mg}$ ivermectin and $150 \mathrm{mg}$ praziquantel in February 2020, i.e., four months before the test. The study was a part of larger research where horses were fed supplemental vegetable oils with or without vitamin E. All of the horses were fed a basal diet formed on oat and concentrate (muesli) 
(Livery Mix, Saracen, Aylesford, Kent, UK-ingredients composition: oatfeed, barley flakes, lucerne pellets, molasses, corn flakes, bean flakes, vitamin and minerals; Baileys Racehorse Cubes, Baileys Horse Feed, Braintree, Essex, UK-ingredients composition: micronized wheat, nutritionally improved straw, wheatfeed, distillers' grains, micronized soya beans, molasses, soya oil, calcium carbonate, vitamins and minerals, calcined magnesite, sodium chloride) and roughage (meadow hay) according to the requirements for racehorse based on Nutrient Requirements of Horses [33]. Horses, except for the control group (group 4), were supplemented with vegetable oils in the amount of $0.5 \mathrm{~mL} /$ day $/ \mathrm{kg}$ body weight and with or without vitamin E for 60 days (Table 1). Supplementation was preceded by a two-week adaptation period. Horses were fed three times a day. Water and mineral salt (Lisal, Kłodawa, Poland) were provided ad libitum.

Table 1. The division into experimental groups.

\begin{tabular}{ccc}
\hline Group & Oil & Numbers of Horses \\
\hline 1 & Soybean & $n=7(4$ oo, $3 \times x)$ \\
2 & Linseed & $n=7(3$ oo, $4 \mathrm{xx})$ \\
3 & linseed + vitamin E & $n=6(2 \mathrm{oo}, 4 \mathrm{xx})$ \\
4 & - & $n=7(3 \mathrm{oo}, 4 \mathrm{xx})$ \\
\hline
\end{tabular}

\subsection{Samples Collection}

Fresh stool samples were collected individually from each animal in the early morning hours on 22 June 2020. Each sample was collected into sterile containers $(15 \mathrm{~mL})$ immediately after defecation. Then, they were cooled down to the temperature of $4{ }^{\circ} \mathrm{C}$ for the time of transport (15 $\mathrm{min})$ and then analyzed.

\subsection{Parasitological Analysis}

Qualitative parasitological analysis was carried out using the flotation method of $2 \mathrm{~g}$ of homogenized fecal samples in a supersaturated $\mathrm{NaCl}$ solution, prepared $24 \mathrm{~h}$ prior to the analysis. The quantitative analysis was performed with McMaster's method, under a light microscope (Delta Optical ProteOne) in McMaster chambers [34].

Parasitic larvae and eggs of botflies were identified based on egg chorion as well as oral hooks and body spines shape and number with the use of keys by Draber-Mońko [35] and $\mathrm{Li}$ et al. [36]. Families of Nematoda were determined based on the shape and measurements of the eggs.

\subsection{Data Analysis}

The obtained results were analyzed in Statistica software (v. 13.3, StatSoft Inc., Tulsa, OK, USA). The normality of the data distribution was checked using Shapiro-Wilk's test, which proved the non-normality distribution of the results. In consequence, the differences were determined with the nonparametric Mann-Whitney's U-test and Kruskal-Wallis test. Correlations were calculated using Spearman's correlation test.

\section{Results}

Stool examination revealed that among 27 horses dewormed in 25 February 2020 were confirmed to host eggs and larvae of members of at least one family of parasites in June 2020. The most prevalent endoparasites of examined horses were Strongylidae Baird, 1856 (ova) - accounting for $86 \%$ cases of parasitism in Thoroughbreds and $100 \%$ in Arabian horses (Figures 1 and 2a). In 33\% of horses from both breed representatives of Strongyloididae Chitwood and McIntosh, 1934 (ova) were also observed (Figure 2b). Eggs and larvae of botflies from Gasterophilus cf pecorum (Fabricius, 1794) (Diptera: Oestridae) occurred in one Arabian horse and one Thoroughbred (Figure 3a,b). Moreover, in one Arabian horse, the presence of alive Paramecium sp. specimen was noted (Figure 3c). 


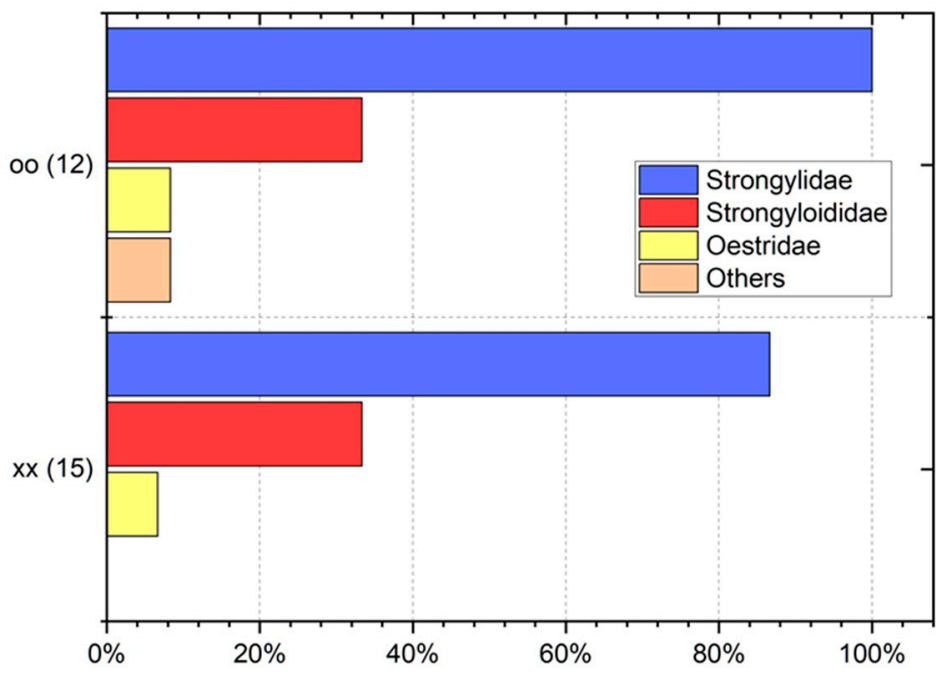

Figure 1. Prevalence of detected organisms in studied horse breeds.

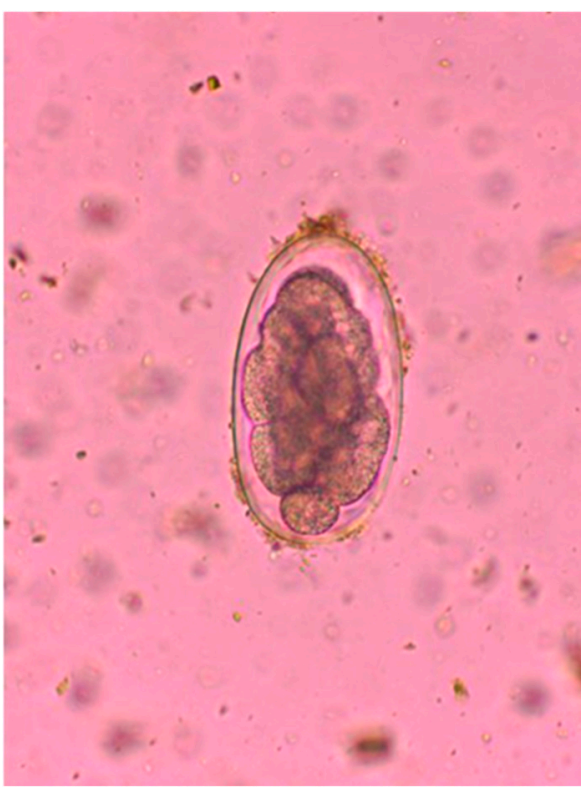

(a)

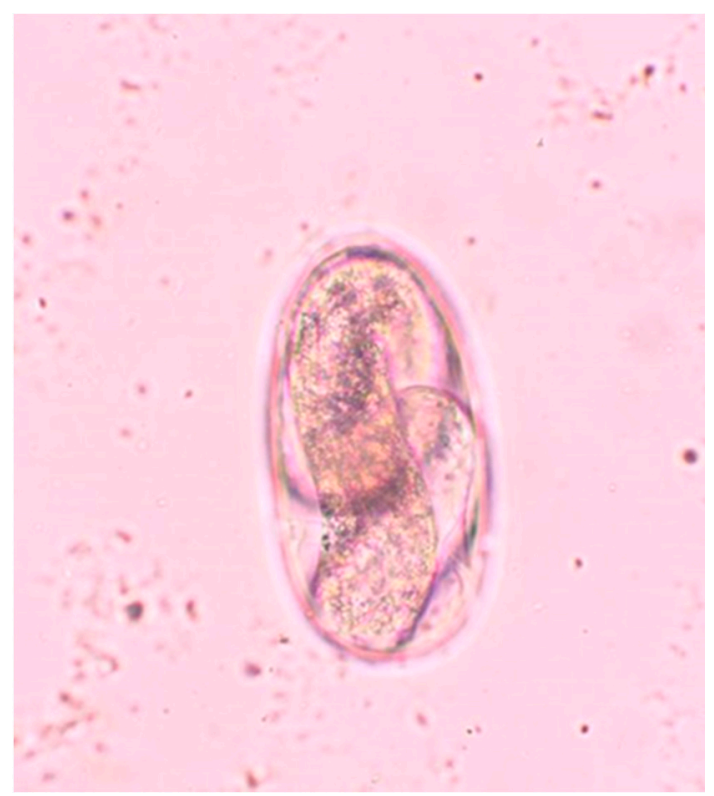

(b)

Figure 2. Eggs detected in fecal samples: (a) Strongylidae; (b) Strongyloididae; not to scale.

The McMaster stool analysis showed that the mean eggs per gram (EPG) coefficient for Strongylidae was 529 in Arabian horses and 530 in Thoroughbreds, whereas for Strongyloididae it was 29 vs. 43 , respectively. The differences were not statistically significant. The minimal and maximal observed number of eggs in stool samples in Arabian horses were 200-1850 (Strongylidae) and 50-200 (Strongyloididae) while in Thoroughbreds, the scopes were 50-1850 (Strongylidae) and 50-300 (Strongyloididae) (Figure 4).

Parasitic co-invasions were also observed. In $42 \%$ of Arabian horses Strongylidae occurred along with other parasites, while in Thoroughbreds the share of parasitic cooccurrence was $38 \%$ of all cases of parasitism (Figure 4). In addition, when analyzing the infestation data on particular individuals, it was noticed that in the case of co-invasions of Strongylidae + botflies, horse no. 1 (group 2) was characterized by less than half the number of strongyles compared to Oestridae, while in horse no. 20 (group 3), Strongylidae were almost three times more numerous than botflies. 


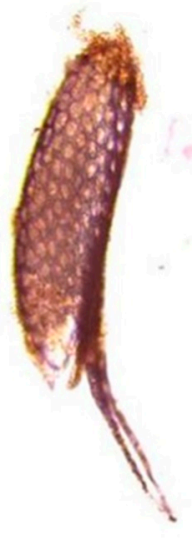

(a)

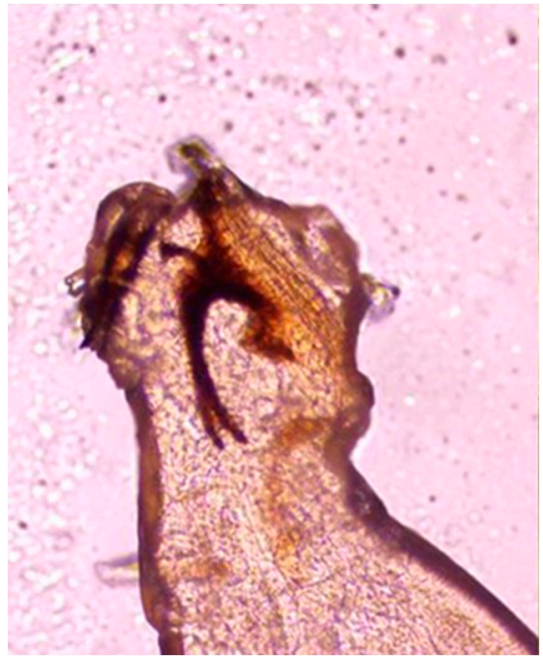

(b)

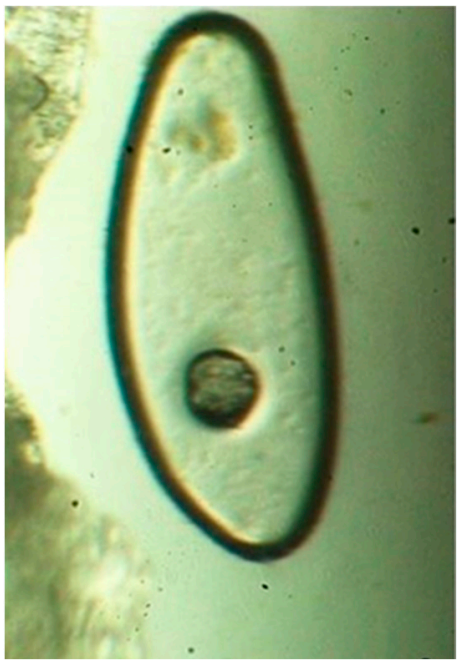

(c)

Figure 3. Organisms detected in fecal samples: (a) G. pecorum-inactive egg; (b) G. pecorum-larval head and oral hooks; (c) Paramecium sp.; not to scale.

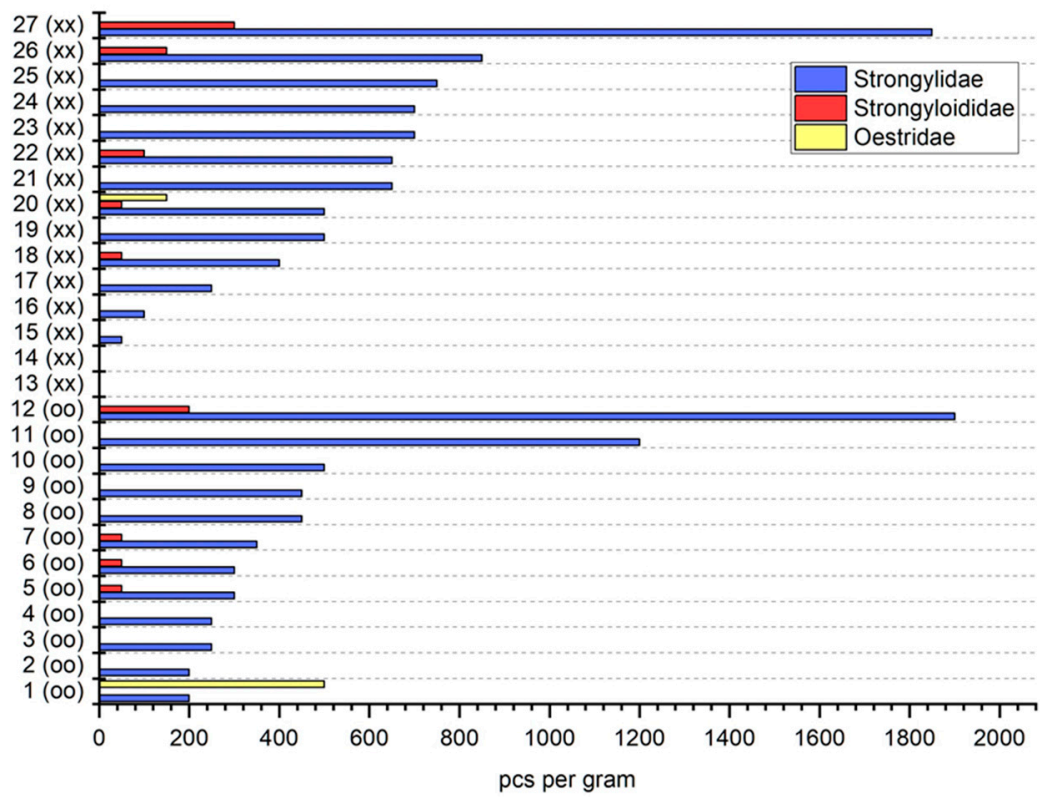

Figure 4. Numbers of eggs/larvae of parasites in stool samples of Arabian horses and Thoroughbreds.

Statistical analysis of the difference of eggs/larvae of parasites in stool samples of Arabian horses and Thoroughbreds was conducted using Mann-Whitney's U-test. In this case, it appeared that the differences are statistically insignificant for alfa 0.05 . This is manifested by the value of the $p$ coefficient (Strongylidae $p=0.492$; Strongyloididae $p=0.456$; Oestridae $p=0.709$ ), supported by the box whiskers graphs presented in the Figure 5. It, therefore, can be concluded that the horses of different breeds are not more susceptible to parasites.

Effects on feed additives on prevalence values of parasites in four experimental groups are presented in Figure 6. The second group, fed with the addition of pure linseed oil, was characterized by the lowest prevalence of Strongylidae (71\% vs. $100 \%$ in other groups), absence of Strongyloididae (vs. $14 \%, 50 \%$ and $71 \%$ in groups 1,3 and 4 , respectively) and the lowest share of horses infested with botflies $(14 \%)$ compared to group $3(17 \%)$. Groups 1 and 4 , in turn, were free from Gasterophilus sp. 

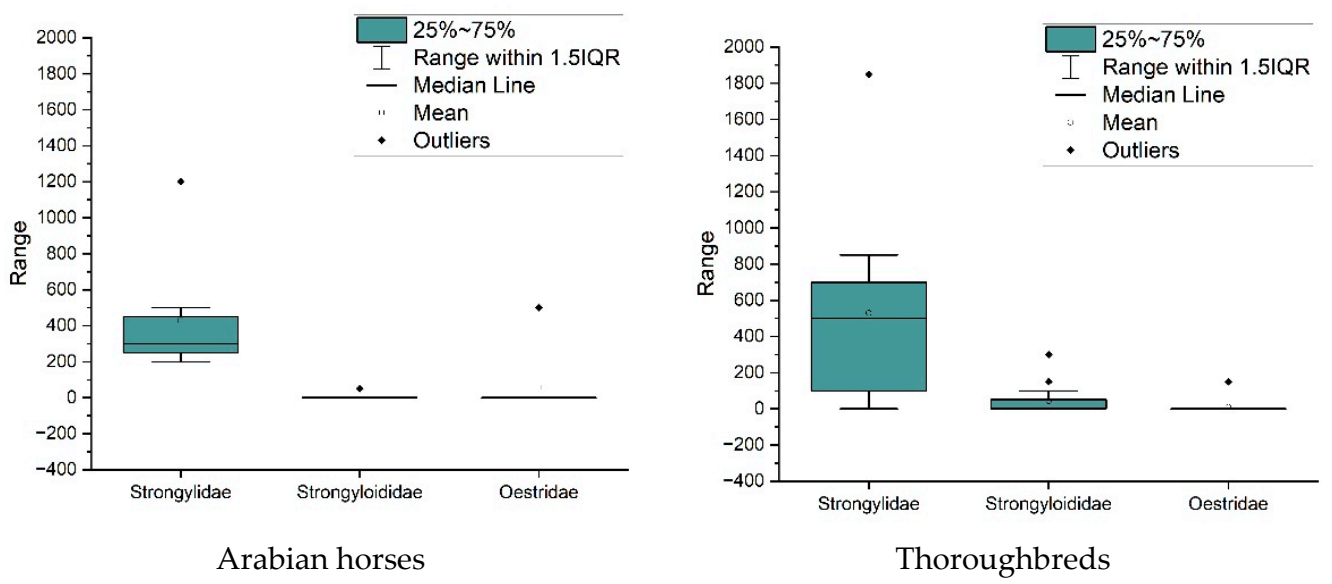

Figure 5. Box whiskers chart of numbers of eggs/larvae of parasites in stool samples of Arabian horses and Thoroughbreds.

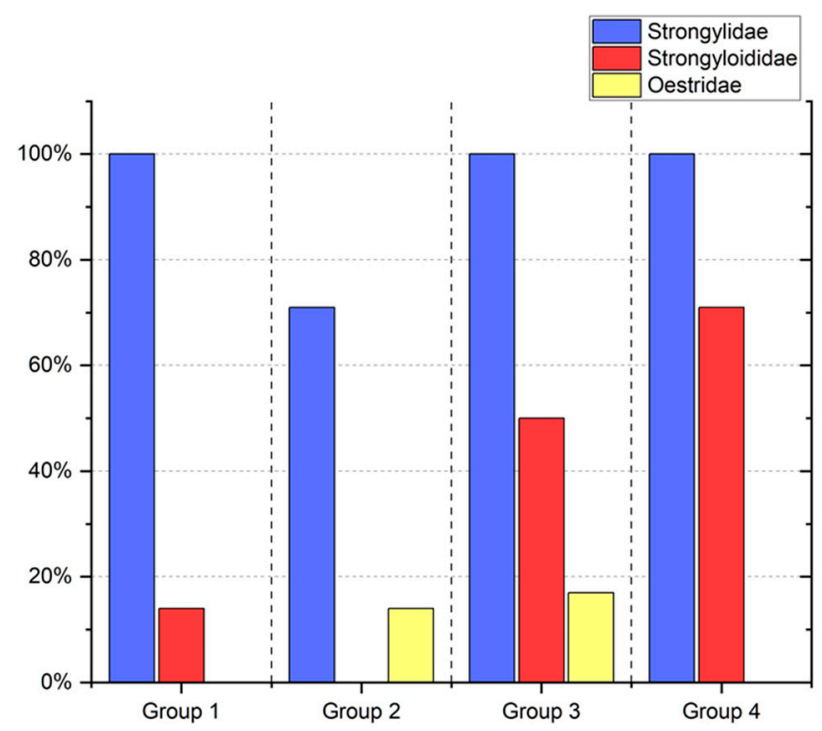

Figure 6. Prevalence of parasites in the experimental groups (group 1—supplemented with soybean oil, group 2-supplemented with linseed oil, group 3-supplemented with linseed oil and vitamin E, group 4-control group).

Mean numbers of parasitic larvae and/or eggs in $1 \mathrm{~g}$ of feces for each group of horses are shown in Figure 7. The highest values (850-Strongylidae and 114-Strongyloididae) were revealed in the control group (group 4), fed with no additives (vs. 586, 164, 513Strongylidae and 7, 0, 25-Strongyloididae, in groups 1, 2 and 3, respectively). Only Gasterophilus eggs and larvae were more numerous in group 2 than in group 3 (71 vs. 25).

The impact of feed additives on the EPG coefficient for experimental groups was determined using Kruskal-Wallis analysis of ranks. This test was used due to the nonnormality distribution of the results, as well as the necessity of comparing more than two groups. Considering the number of eggs/larvae in $1 \mathrm{~g}$ of feces, it was apparent that the most justified option was to verify the difference of Strongylidae in between the groups. The Oeastridae were detected only in 2 of 4 groups, so the difference between the groups was evident. A similar tendency is visible in Strongyloididae. According to Kruskal-Wallis analysis, the difference between the groups of Strongylidae is statistically significant $(p=0.0143)$. More precisely - at least one group was found to differ from the others with a significance level of 0.05 . Closer analysis revealed that only the second group is different from the 1 group (Table 2). Closer inspection of the $p$ coefficient revealed that, although differences of group 1 and 2 are significant, all other relations are close to 
being significant in terms of statistics. Apart from the clear relation of groups 1 vs. 2, the next statistical correspondence was visible for groups 2 vs. 4 where $p=0.054$, which is close to being considered as statistically valid. Subsequently, the differences of groups 2 vs. $3(p=0.097)$ represented less significant differences compared to the previously mentioned groups but was still worthy of consideration. For a greater number of horses or tests performed in a longer duration, the differences of group 2 from the others could appear statistically important. Therefore focusing the investigation on this group seemed to be justified. Moreover, it should be noted that apart from group 2, the other of the $p$ values were equal to 1 , which are safe to be considered as unimportant from a statistical perspective.

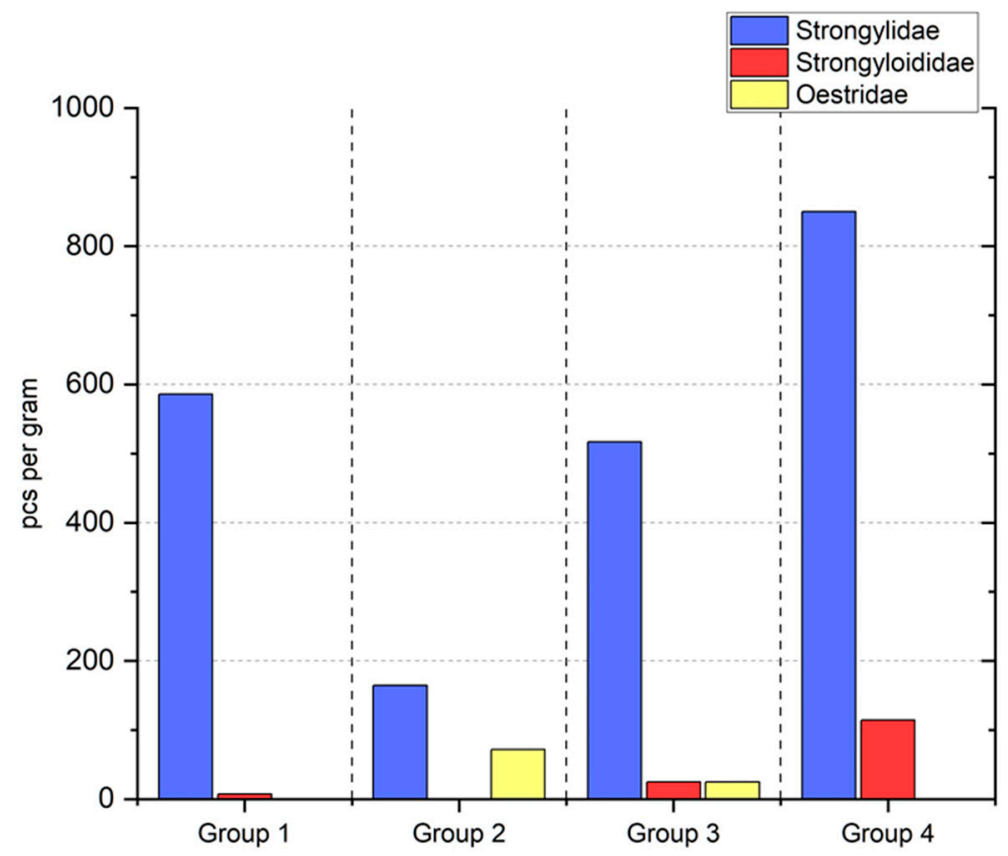

Figure 7. Mean numbers of eggs/larvae in $1 \mathrm{~g}$ of faeces in the experimental groups (group 1supplemented with soybean oil, group 2-supplemented with linseed oil, group 3-supplemented with linseed oil and vitamin E, group 4-control group).

Table 2. Multiple comparisons between the groups (group 1-supplemented with soybean oil, group 2-supplemented with linseed oil, group 3-supplemented with linseed oil and vitamin E, group 4 - control group) ( $R$ stands for the value of an average rank; a bolded values indicates a statistically significant difference for $\alpha=0.05)$.

\begin{tabular}{ccccc}
\hline & Group 1 & Group 2 & Group 3 & Group 4 \\
& R: 15.286 & R: 5.2857 & R: 14.750 & R: 16.875 \\
\hline \multirow{2}{*}{ Group 1 } & & $p=\mathbf{0 . 0 4 8 9 0 6}$ & $p=1$ & $p=1$ \\
& & $\mathbf{z}=\mathbf{2 . 6 4 5 7}$ & $\mathrm{z}=0.1361$ & $\mathrm{z}=0.3585$ \\
\hline \multirow{2}{*}{ Group 2 } & $p=\mathbf{0 . 0 4 8 9 0 6}$ & & $p=0.096828$ & $p=0.053553$ \\
& $\mathbf{z}=\mathbf{2 . 6 4 5 7}$ & & $\mathrm{z}=2.4057$ & $\mathrm{z}=2.6148$ \\
\hline \multirow{2}{*}{ Group 3 } & $p=1$ & $p=0.096828$ & & $p=1$ \\
& $\mathrm{z}=0.1361$ & $\mathrm{z}=2.4057$ & & $\mathrm{z}=0.4655$ \\
\hline \multirow{2}{*}{ Group 4 } & $p=1$ & $p=0.053553$ & $p=1$ & \\
& $\mathrm{z}=0.3585$ & $\mathrm{z}=2.6148$ & $\mathrm{z}=0.4655$ & \\
\hline
\end{tabular}

The test of Kruskal-Wallis is essentially ANOVA for ranks. The ranks are shown in Figure 8 . In general, the greater the sum of ranks, the greater number of pieces in gram of feces for a given group. 


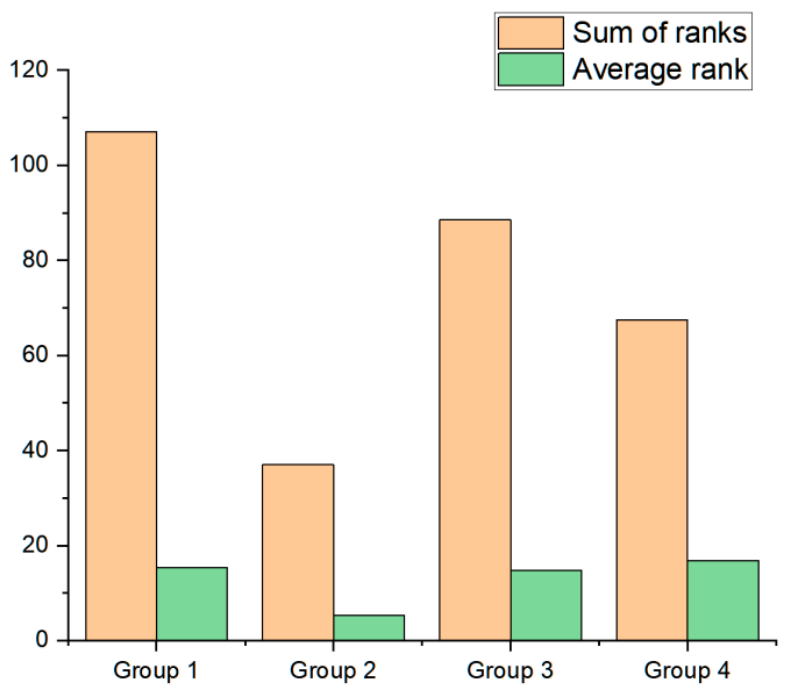

Figure 8. Ranks of Kruskal-Wallis analysis.

The correlation between the types of parasite found in the stool was verified with the aid of Spearman correlation of ranks. This was done in order to verify if the occurrence of a parasite can be a reason to suspect the occurrence of the other types. However, the analysis revealed no significant correlation, which means that the parasites must be considered individually. The occurrence of one type does not mean the other type is also present. The results of the correlation are shown in Table 3.

Table 3. Spearman correlation of ranks for parasites in stools.

\begin{tabular}{cccc}
\hline & Strongylidae & Strongyloididae & Oestridae \\
\hline Strongylidae & 1.000000 & 0.346247 & -0.106779 \\
Strongyloididae & 0.346247 & 1.000000 & 0.083236 \\
Oestridae & -0.106779 & 0.083236 & 1.000000 \\
\hline
\end{tabular}

\section{Discussion}

The occurrence of endoparasites in animals treated with parasiticide containing ivermectin is accordant with the results of Kyvsgaard et al. [37], who observed the reappearance of strongyle eggs within 60 days post deworming.

The research indicated that the factor of breed does not significantly affect the number of gastrointestinal parasites. A comparison between horse breeds and their strongylid burden was included in the research by Kuzmina et al. [38], who revealed that Thoroughbreds, Ukrainian Saddlers and Russian Racers had much higher EPG values compared to non-breed horses. Still, the latter cannot be fully compared to our results, because we only analyzed two breeds of horses.

Mean EPG coefficients for Strongylidae, despite not being significantly different between Thoroughbreds and Arabian horses (530 vs. 529) in this study, were lower than the mean values in riding horses examined in Ukraine [38]. Below, the listed horses represented groups closest to our study, i.e., a similar sample size, dewormed 1-2 a year, with macrocyclic lactones, including: Ukrainian Saddlers (EPG $=796.9 ; n=8$ (Donetsk), $\mathrm{EPG}=680.8 ; n=13$ (Kharkov) and EPG $=889.6 ; n=12$ (Voronkovsky)) and Russian Racers $(\mathrm{EPG}=583.3 ; n=9)$. As for the Thoroughbreds, in the cited research, this breed underwent one or no deworming procedures per year and thus its mean EPG was considerably higher than the present-1428.1. Our results were higher than observed by Forteau et al. [39], in which case horses grazing separately were characterized by a mean EPG of 400, while when mixed with cattle, it was 230. The difference was attributed to the dilution effect. Jenkins et al. [40] revealed that EPG values for wild horses of Sable Islands, Canada, range from 669 to 1105, depending on the season. 
Repeatable observations of relatively high amounts of strongyle ova in feces of regularly dewormed animals may result, in addition to the aforementioned cessation of biological activity of ivermectin, from the development of the drug-resistance in representatives of Strongylidae. The latter, in turn, may be an outcome of incorrect use of the named anthelmintics $[10,12]$. This assumption is partly supported by already cited results by Kuzmina et al. [38], who revealed that a statistically significant difference in EPG values was present only between horses with rare to lack of anthelmintic treatments but not between horses dewormed 1-2 a year vs. 3-4 times or more with macrocyclic lactones.

In both breeds, the most numerous were found for Strongylidae, which are the most common and geographically widespread equine endoparasites [41,42]. Our data on prevalence correspond with those by Ramey and Nielsen [43], wherein $78 \%$ of examined horses were infested by strongylids. Also, studies by Eslami et al. [44], Bulgaru and Tudor [45] as well as Ola-Fadunsin et al. [46] indicated Strongylidae as the most abundant group; however, the values of prevalence were lower- $28.3 \%, 27.92 \%$ and $33.33 \%$, respectively, vs. $78 \%$ (Thoroughbreds) and 100\% (Arabian horses) in the present research.

Shares of parasitic co-invasions observed in this study (42\% in Arabian horses and $38 \%$ in Thoroughbreds) were slightly lower than in horses and donkeys studied by Wannas et al. [47] in Iraq-50\% and $71.42 \%$, respectively. Lower shares of mixed invasions in equids were recorded by Sultan et al. [48] in Ethiopia, wherein only donkeys (8.41\%) were simultaneously infested with Oestridae + Ascarididae (1 case) and, as in this study, botflies + Strongylidae ( 25 cases). There is a possibility that upon decreasing efficiency of the most use, broad-spectrum parasiticides, shares of mixed infection in horses may increase.

An atypical observation were eggs along with the first and the second stage larvae of G. pecorum (Figure 3a,b) at the total absence of the third stadium, which typically completes development in the rectum after which larvae exit the host and pupation takes place in the external environment [35]. Immature larvae were observed only in the feces of individuals fed with the addition of linseed oil-pure and mixed with vitamin E. A possible explanation of this situation was providing these horses with hay infested with $G$. pecorum ova. Oviposition on vegetation, especially grasses, is a peculiarity of this botfly species. Eggs retain the ability to infect equidae for more than 250 days and usually hatch in the horse's mouth after being soaked for 3-5 min of chewing $[35,49,50]$. On the other hand, in the case of excessive dehydration of the egg shell, which may have occurred during the drying and storage of hay, the larvae either lost the ability to hatch or managed to do it too late, i.e., already in the gastric contents. There they could not continue the regular life cycle, i.e., parasitize on the soft palate/esophagus and/or stomach and complete development in the rectum as the third stage [35,51]. The inability of G. pecorum to hatch from dried eggs was stated by Liu et al. [49]. Moreover, unfavorable conditions for continuing the development in the stomach combined with the administration of feed rich in mucosa-protective linseed oil and loose consistency of faeces, in individuals with immature larvae detected, may have prevented parasites from proper attachment and, as a result, contributed to their premature elimination from the digestive system of horses, along with the feces. The loose consistency of the stool was only observed in the morningafter training. Intensive efforts and prevailing weather conditions (high temperature and air humidity) caused a greater demand for water while reducing the consumption of solid feed by horses, which directly influenced the dilution of the feces and caused faster passage of the intestinal content. During the fortnight preceding stool sampling, $60-90 \%$ relative humidity, as well as a temperature minimum range of $14-19^{\circ} \mathrm{C}$ and a maximum range of $18-32{ }^{\circ} \mathrm{C}$ were observed (data were obtained from the Institute of Meteorology and Water Management in Wrocław, Poland). The presence of ova in the samples was, in turn, an outcome of swallowing and excretion by animals completely dried and so inactive eggs. This explanation was also supported by the fact that G. pecorum has been listed in Poland [35,52]. Furthermore, the presence of other representatives of Gasterophilus spp., the oviposition site of which is horse hair and coat, besides above mentioned taxonomic traits of eggs and larvae, was excluded by the daily care of animals, including brushing 
and washing, as well as the lack of access to pastures where the infestation with other botflies could have been the easiest. In the research by Zhang et al. [53], it was revealed that the third stage larvae of G. pecorum are naturally excreted from the host for about 7 months a year. Two peaks of the mentioned process were also observed: peak I-from early April to early May and peak II-from mid-August to early September, even though G. pecorum is an univoltine species, i.e., it produces only one generation a year. During the first peak, larvae were characterized by lower survival and pupation rates along with a longer eclosion period than the parasites derived from the second peak. That could have been attributed to both overdrying of the egg shells and a long period of waiting for the proper host under unfavorable conditions, as in the present case.

Still, our data on the prevalence of Oestridae are considerably lower than presented by Tolliver et al. [54]_USA, Sweeney [55]—Ireland and Lyons et al. [56]—USA, wherein dewormed horses were infested with Gasterophilus larvae at the levels of $94 \%, 90 \%$ and $20 \%$, respectively. The low prevalence of botflies revealed in this study corresponds, in turn, with observations by Sallé et al. [57] on sports horses in northern France, indicating a significant decrease in the numbers of these parasites in the digestive system of horses occurred in recent years. The observed differences may result from distinct methods of research (analysis of dissected digestive tracts vs. coproscopy) and, as already mentioned, the different extent of applied hygienic treatments between slaughter and sports horses.

Also, as indicated by literature data, a few other factors affect infestation by Gasterophilus spp. in horses, among which are geographical location and climate [49], as well as changeable weather conditions (temperature, rainfall, $\mathrm{RH}$ ) in a given locality [53,58]. Huang et al. [59] revealed $100 \%$ prevalence in studied equids (Equus przewalskii, E. hemionus, E. ferus caballus; $n=11$ ) in northern China. These results are convergent with Liu et al. [60], who examined 90 ivermectin-dewormed horses. The prevalence of Gasterophilus larvae was $100 \%$. Identical, $100 \%$ prevalence of G. pecorum was recorded in Iran by Moshaverinia et al. [61] in dissected animals. It is noteworthy to mention that this was the first observation of the species in this country. However, one should remember that in the era of climate change and the extensive transport of horses between countries and continents, in the future, more Oestridae species are very likely to be introduced in areas where they did not exist before.

In horse no. 1 we could observe an antagonistic interaction between co-occurring strongyles and botflies. This mechanism has already been described in humans [62]; however, the above presented results of statistical analysis excluded a supposition of any correlation between the presence of a different type of parasites. Another explanation may be an influence of pure linseed oil on parasites. Horse no. 1 was assigned to group number 2 (pure linseed oil), whereas number 20 was assigned to the third group (linseed oil + vitamin E). This confirms already revealed statistical differences between groupsin particular animals_-representing these groups. Possible antiparasitic effects of pure, and/or mixed with Chenopodium, linseed oil were mentioned by Morcos [17] and Lyons et al. [18]; however, these mentions come from the 1950s and 1960s, i.e., before the invention of the contemporary parasiticides. However, present results seem to confirm the sense of these, already historical, attempts to control helminths with the use of natural substances. As stated in the beginning, even macrocyclic lactones are being slowly resisted by many parasites, so any additional, non-chemical, antiparasitic agents may be crucial in breeding animals in the future. This makes feed additives properties worth further detailed research.

Our study revealed no impact of the addition of vitamin E+linseed oil mixture on parasites. It is inconsistent with the only available data on tocopherol addition and helminth burden in animals, i.e., the work by De Wolf et al. [63] who investigated its effect on an experimental Haemonchus contortus (Trichostrongylidae) infestation in lambs. Authors found a positive influence of the D- $\alpha$-tocopherol on the parasitic burden, which was $49 \%$ lower in lambs from the experimental group $(n=10)$, compared to the control $(n=10)$. The discrepancies in observations may be due to few factors, i.e., different species and age of animals, different parasites studied and an experimental (five weeks from the start of 
supplementation with the third stage of the larvae) vs. natural infection with helminths. Still, contradictory results and a lack of additional data on the subject point to the need for more studies.

Finally, an interesting side observation was the alive representative of Parameciidae (Figure 3c) in one sample; we did not find a similar case in the available literature.

\section{Conclusions}

The main conclusion arising from the results of the present paper is that the addition of pure linseed oil significantly reduces the burden of Strongylidae in examined horses. The statistical analysis revealed that only linseed oil and soybean represent valid differences, but considering the $p$ values of multiple comparisons, and the fact that these studies are preliminary, further consideration of linseed oil appears to be justified. Therefore, the substance is worth analyzing further, including through tests on other groups of farm animals. The study also indicates that there is no impact of tocopherol addition on the parasitic burden in horses, which is in contradiction to, however, limited, literature data and thus should be studied in more detail. Moreover, among tested horse breeds, none are more susceptible to the parasitic infestation, regardless of the parasite's taxon, and the presence of particular taxa does not affect one another.

Author Contributions: Conceptualization, W.G.; methodology, W.G., K.W.; formal analysis, W.G., K.W., P.C. and A.G.; investigation, W.G., H.M. and K.W.; data curation, W.G.; writing-original draft preparation, W.G., H.M., K.W., A.G., A.W. and N.S.; writing-review and editing, W.G., H.M.; visualization, W.G.; supervision, M.S.; project administration, W.G. All authors have read and agreed to the published version of the manuscript.

Funding: This research received no external funding.

Institutional Review Board Statement: Not applicable (samples of parasites from faces). Consent to participate is not applicable pursuant to the Polish Act of 15 January 2015 "On the protection of animals used for scientific or educational purposes".

Informed Consent Statement: Not applicable.

Data Availability Statement: The data presented in this study are available on request from the corresponding author. The data are not publicly available for privacy reasons.

Acknowledgments: The authors would like to thank the trainer and horse owners from Wroclaw Racetrack-Wrocławski Tor Wyścigów Konnych Partynice for their help with the study.

Conflicts of Interest: The authors declare no conflict of interest.

\section{References}

1. Czapla, D.; Seremak, B.; Kruzhel, B.; Vovk, S. Parasitic fauna of gastrointestinal tract of horses and evaluation of deworming effectiveness. Acta Sci. Pol. Zootech. 2015, 14, 61-68.

2. Traversa, D.; Castagna, G.; von Samson-Himmelstjerna, G.; Meloni, S.; Bartolini, R.; Geurden, T.; Pearce, M.C.; Woringer, E.; Besognet, B.; Milillo, P.; et al. Efficacy of major anthelmintics against horse cyathostomins in France. Vet. Parasitol. 2012, 188, 294-300. [CrossRef] [PubMed]

3. Raś-Noryńska, M.; Sokół, R. Controlling parasitic invasion in horses. Życie Wet. 2011, 86, $299-301$.

4. Comer, K.; Coles, G.C.; Hillyer, M.H.M. A national survey for anthelmintic resistant nematodes in thoroughbreds. In Proceedings of the Eighteenth International Conference of the World Association for the Advancement of Veterinary Parasitology, Stresa, Italy, 26-30 August 2001; Benedettina: Parma, Italy, 2001; p. 166.

5. Lind, E.O.; Rautalinko, E.; Uggla, A.; Waller, P.J.; Morrison, D.A.; Höglund, J. Parasite control practices on Swedish horse farms. Acta Vet. Scand. 2007, 49, 25. [CrossRef] [PubMed]

6. Jagła, E.; Śpiewak, J.; Zaleśny, G.; Popiołek, M. Effect of storage and preservation of horse faecal samples on the detectability and viability of strongylid nematode eggs and larvae. Bull. Vet. Inst. Pulawy 2013, 57, 161-165. [CrossRef]

7. Lloyd, S.; Smith, J.; Connan, R.M.; Hatcher, M.A.; Hedges, T.R.; Humphrey, D.J.; Jones, A.C. Parasite control methods used by horse owners: Factors predisposing to the development of anthelmintic resistance in nematodes. Vet. Rec. 2000, 146, 487-492. [CrossRef]

8. Kaplan, R.M. Drug resistance in nematodes of veterinary importance: A status report. Trends Parasitol. 2004, 20 , 477-481. [CrossRef] 
9. Brady, H.A.; Nichols, W.T. Drug resistance in equine parasites: An emerging global problem. J. Equine Vet. Sci. 2009, $29,285-295$. [CrossRef]

10. Daniels, S. Friend or foe? Intestinal parasites of horses and sustainable worm control mechanisms. Vet. Nurs. J. 2019, 34, 72-77. [CrossRef]

11. Raza, A.; Qamar, A.G.; Hayat, K.; Ashraf, S.; Williams, A.R. Anthelmintic resistance and novel control options in equine gastrointestinal nematodes. Parasitology 2019, 146, 425-437. [CrossRef]

12. Tydén, E.; Jansson, A.; Ringmark, S. Parasites in horses kept in a 2.5 year-round grazing system in nordic conditions without supplementary feeding. Animals 2019, 9, 1156. [CrossRef]

13. Kuzmina, T.A.; Kharchenko, V.O. Anthelmintic resistance in cyathostomins of brood horses in Ukraine and influence of anthelmintic treatments on strongylid community structure. Vet. Parasitol. 2008, 154, 277-288. [CrossRef]

14. Relf, V.E.; Lester, H.E.; Morgan, E.R.; Hodgkinson, J.E.; Matthews, J.B. Anthelmintic efficacy on UK Thoroughbred stud farms. Int. J. Parasitol. 2014, 44, 507-514. [CrossRef]

15. Cogley, T.P.; Cogley, M.C. Inter-relationship between Gasterophilus larvae and the horse's gastric and duodenal wall with special reference to penetration. Vet. Parasitol. 1999, 86, 127-142. [CrossRef]

16. Lapointe, J.M.; Celeste, C.; Villeneuve, A. Septic peritonitis due to colonic perforation associated with aberrant migration of a Gasterophilus intestinalis larva in a horse. Vet. Pathol. 2003, 40, 338-339. [CrossRef]

17. Morcos, Z. Prevalent diseases of race horses in Egypt; conclusion of 1927-1947 observations. Vet. Med. 1947, 42, 94-97.

18. Lyons, E.T.; Tolliver, S.C.; Drudge, J.H. Historical perspective of cyathostomes: Prevalence, treatment and control programs. Vet. Parasitol. 1999, 85, 97-112. [CrossRef]

19. Markowiak, P.; Śliżewska, K. The role of probiotics, prebiotics and synbiotics in animal nutrition. Gut Pathog. 2018, 10, 21. [CrossRef] [PubMed]

20. Athanasiadou, S.; Githiori, J.; Kyriazakis, I. Medicinal plants for helminth parasite control: Facts and fiction. Animals 2007, 1, 1392-1400. [CrossRef] [PubMed]

21. Huang, Q.; Liu, X.; Zhao, G.; Hu, T.; Wang, Y. Potential and challenges of tannins as an alternative to in-feed antibiotics for farm animal production. Anim. Nutr. 2018, 4, 137-150. [CrossRef] [PubMed]

22. Anthony, J.P.; Fyfe, L.; Smith, H. Plant active components-a resource for antiparasitic agents? Trends Parasitol. 2005, 21, 462-468. [CrossRef]

23. Williams, C.A.; Lamprecht, E.D. Some commonly fed herbs and other functional foods in equine nutrition: A review. Vet. J. 2008, 178, 21-31. [CrossRef]

24. Waller, P.J.; Bernes, G.; Thamsborg, S.; Sukura, A.; Richter, S.H.; Ingerbrigsten, K.; Höglund, J. Plants as de-worming agents of livestock in the Nordic countries: Historical perspective, popular beliefs and prospects for the future. Acta Vet. Scand. 2001, 42, 31-44. [CrossRef] [PubMed]

25. El Shenawy, N.; Soliman, M.F.M.; Reyad, S.I. The effect of antioxidant properties of aqueous garlic extract and Nigella sativa as anti-schistosomiasis agents in mice. Rev. Inst. Med. Trop. Sao Paulo 2008, 50, 29-36. [CrossRef]

26. Szewc, M.; De Waal, T.; Zintl, A. Biological methods for control of gastrointestinal nematodes. Vet. J. 2021, 268, 105602. [CrossRef] [PubMed]

27. Kronfeld, D.S.; Holland, J.L.; Rich, G.A.; Meacham, T.N.; Fontenot, J.P.; Sklan, D.J.; Harris, P.A. Fat digestibility in Equus caballus follows increasing first-order kinetics. J. Anim. Sci. 2004, 82, 1773-1780. [CrossRef]

28. O'Neil, W.; McKee, S.; Clarke, A.F. Flaxseed (Linum usitatissimum) supplementation associated with reduced skin test lesional area in horses with Culicides hypersensitivity. Can. J. Vet. Res. 2002, 66, 272-277.

29. de Almeida, F.Q.; de Godoi, F.N. Soybean oil in horses' diets. In Soybean and Nutrition; El-Shemy, H., Ed.; IntechOpen: London, UK, 2011; pp. 251-268. [CrossRef]

30. Okai, K.; Taharaguchi, S.; Orita, Y.; Yokota, H.; Taniyama, H. Comparative endoscopic evaluation of normal and ulcerated gastric mucosae in Thoroughbred foals. J. Vet. Med. Sci. 2015, 77, 449-453. [CrossRef] [PubMed]

31. Elghandour, M.M.M.Y.; Reddy, P.R.K.; Salem, A.Z.M.; Reddy, P.P.R.; Hyder, I.; Barbabosa-Pliego, A.; Yasaswini, D. Plant bioactives and extracts as feed additives in horse nutrition. J. Equine Vet. Sci. 2018, 69, 66-77. [CrossRef]

32. Saastamoinen, M.; Särkijärvi, S. Effect of linseed (Linum usitatissimum) groats-based mixed feed supplements on diet nutrient digestibility and blood parameters of horses. Animals 2020, 10, 272. [CrossRef] [PubMed]

33. National Research Council (NRC). Nutrient Requirements of Horses, 6th ed.; National Academy Press: Washington, DC, USA, 2007.

34. Pereckiene, A.; Kaziūnaitè, V.; Vyšniauskas, A.; Petkevičius, S.; Malakauskas, A.; Šarkūnas, M.; Taylor, M.A. A comparison of modifications of the McMaster method for the enumeration of Ascaris suum eggs in pig faecal samples. Vet. Parasitol. 2007, 149, 111-116. [CrossRef] [PubMed]

35. Draber-Mońko, A. Klucze do Oznaczania Owadów Polski. Cz. XXVIII Muchówki-Diptera, zesz. 75. Gziki-Gastherophilidae; PWN Warszawa, Poland, 1969.

36. Li, X.Y.; Pape, T.; Zhang, D. Taxonomic review of Gasterophilus (Oestridae, Gasterophilinae) of the world, with updated nomenclature, keys, biological notes, and distributions. ZooKeys 2019, 891, 119-156. [CrossRef] [PubMed]

37. Kyvsgaard, N.C.; Lindbom, J.; Andreasen, L.L.; Luna-Olivares, L.A.; Nielsen, M.K.; Monrad, J. Prevalence of strongyles and efficacy of fenbendazole and ivermectin in working horses in El Sauce, Nicaragua. Vet. Parasitol. 2011, 181, 248-254. [CrossRef] 
38. Kuzmina, T.A.; Dzeverin, I.; Kharchenko, V.A. Strongylids in domestic horses: Influence of horse age, breed and deworming programs on the strongyle parasite community. Vet. Parasitol. 2016, 227, 56-63. [CrossRef]

39. Forteau, L.; Dumont, B.; Sallé, G.; Bigot, G.; Fleurance, G. Horses grazing with cattle have reduced strongyle egg count due to the dilution effect and increased reliance on macrocyclic lactones in mixed farms. Animals 2020, 14, 1076-1082. [CrossRef]

40. Jenkins, E.; Backwell, A.L.; Bellaw, J.; Colpitts, J.; Liboiron, A.; McRuer, D.; Medill, S.; Parker, S.; Shury, T.; Smith, M.; et al. Not playing by the rules: Unusual patterns in the epidemiology of parasites in a natural population of feral horses (Equus caballus) on Sable Island, Canada. Int. J. Parasitol. Parasites Wildl. 2020, 11, 183-190. [CrossRef]

41. Hamed, M.I.; El-Allawy, T.A.A.; Hassnein, E.A. Prevalence and anthelmintic resistance of strongyle infection of donkeys in El-Wadi El-Gadid, Egypt. J. Adv. Vet. Res. 2019, 9, 144-150.

42. Kaur, S.; Singh, E.; Singla, L.D. Strongylosis in equine: An overview. J. Entomol. Zool. Stud. 2019, 7, 43-46.

43. Ramey, D.W.; Nielsen, M.K. Limited strongyle parasite occurrence in horses kept in an arid environment. Equine Vet. Educ. 2020, 32, 37-40. [CrossRef]

44. Eslami, A.; Bokai, S.; Tabatabai, V. Equine parasites in Iran. J. Equine Vet. Sci. 2005, 25, 143-144. [CrossRef]

45. Bulgaru, A.; Tudor, P. The prevalence of helminth parasites in horses raised in modern conditions. Sci. Works Ser. C Vet. Med. 2016, 61, 271-274.

46. Ola-Fadunsin, S.D.; Daodu, O.B.; Hussain, K.; Ganiyu, I.A.; Rabiu, M.; Sanda, I.M.; Adah, A.S.; Adah, A.D.; Aiyedun, J.O. Gastrointestinal parasites of horses (Equus caballus Linnaeus, 1758) and risk factors associated with equine coccidiosis in Kwara and Niger States, Nigeria. Sokoto J. Vet. Sci. 2019, 17, 35-43. [CrossRef]

47. Wannas, H.Y.; Dawood, K.A.; Gassem, G.A. Prevalence of gastro-intestinal parasites in horses and donkeys in Al Diwaniyah Governorate. Al-Qadisiyah J. Vet. Med. Sci. 2012, 11, 148-155. [CrossRef]

48. Sultan, A.; Ayele, G.; Tadesse, B.; Ahmed, A. Prevalence of gastrointestinal parasites of horses and donkeys in Kurfa Chale District, East Hararghe, Ethiopia. Livest. Res. Rural Dev. 2014, 26, 119.

49. Liu, S.H.; Hu, D.F.; Li, K. Oviposition site selection by Gasterophilus pecorum (Diptera: Gasterophilidae) in its habitat in Kalamaili Nature Reserve, Xinjiang, China. Parasite 2015, 22, 34. [CrossRef]

50. Zaheri, B.A.; Ronaghi, H.; Youssefi, M.R.; Hoseini, S.M.; Omidzahir, S.; Dozouri, R.; Eshkevari, S.R.; Mousapour, A. Gasterophilus pecorum and Habronema muscae in Persian onager (Equus hemionus onager), histopathology and parasitology survey. Comp. Clin. Pathol. 2015, 24, 1009-1013. [CrossRef]

51. Smith, M.A.; McGarry, J.W.; Kelly, D.F.; Proudman, C.J. Gasterophilus pecorum in the soft palate of a British pony. Vet. Rec. 2005, 156, 283-284. [CrossRef]

52. Kornaś, S.; Gawor, J.; Skalska, M.; Nowosad, B. Occurrence of botfly in horses from small farms. Medycyna Wet. 2006, $26,452-454$.

53. Zhang, K.; Huang, H.; Zhou, R.; Zhang, B.; Wang, C.; Ente, M.; Li, B.; Zhang, D.; Li, K. The impact of temperature on the life cycle of Gasterophilus pecorum in northwest China. Parasites Vectors 2021, 14, 129. [CrossRef]

54. Tolliver, S.C.; Lyons, E.T.; Drudge, J.H. Prevalence of internal parasites in horses in critical tests of activity of parasiticides over a 28-year period (1956-1983) in Kentucky. Vet. Parasitol. 1987, 23, 273-284. [CrossRef]

55. Sweeney, H.J. The prevalence and pathogenicity of Gasterophilus intestinalis larvae in horses in Ireland. Ir. Vet. J. 1990, 43, 67-73.

56. Lyons, E.T.; Swerczek, T.W.; Tolliver, S.C.; Bair, H.D.; Drudge, J.H.; Ennis, L.E. Prevalence of selected species of internal parasites in equids at necropsy in central Kentucky (1995-1999). Vet. Parasitol. 2000, 92, 51-62. [CrossRef]

57. Sallé, G.; Guillot, J.; Tapprest, J.; Foucher, N.; Sevin, C.; Laugier, C. Compilation of 29 years of postmortem examinations identifies major shifts in equine parasite prevalence from 2000 onwards. Int. J. Parasitol. 2020, 50, 125-132. [CrossRef]

58. Pilo, C.; Altea, A.; Scala, A. Gasterophilosis in horses in Sardinia (Italy): Effect of meteorological variables on adult egg-laying activity and presence of larvae in the digestive tract, and update of species. Parasitol. Res. 2015, 114, 1693-1702. [CrossRef]

59. Huang, H.; Zhang, B.; Chu, H.; Zhang, D.; Li, K. Gasterophilus (Diptera, Gasterophilidae) infestation of equids in the Kalamaili Nature Reserve, China. Parasite 2016, 23, 36. [CrossRef]

60. Liu, S.H.; Li, K.; Hu, D.F. The incidence and species composition of Gasterophilus (Diptera, Gasterophilidae) causing equine myiasis in northern Xinjiang, China. Vet. Parasitol. 2016, 217, 36-38. [CrossRef]

61. Moshaverinia, A.; Baratpour, A.; Abedi, V.; Mohammadi-Yekta, M. Gasterophilosis in Turkmen horses caused by Gasterophilus pecorum (Diptera, Oestridae). Sci. Parasitol. 2016, 17, 49-52.

62. Blackwell, A.D.; Martin, M.; Kaplan, H.; Gurven, M. Antagonism between two intestinal parasites in humans: The importance of co-infection for infection risk and recovery dynamics. Proc. Biol. Sci. 2013, 280, 20131671. [CrossRef] [PubMed]

63. De Wolf, B.M.; Zajac, A.M.; Hoffer, K.A.; Sartini, B.L.; Bowdridge, S.; LaRoith, T.; Petersson, K.H. The effect of vitamin E supplementation on an experimental Haemonchus contortus infection in lambs. Vet. Parasitol. 2014, 205, 140-149. [CrossRef] 